\title{
Rancang Bangun Pengatur Suhu Dan Kelembaban Ruang Server Berbasis IoT
}

\author{
Muhammad Irvan Zarkasi ${ }^{1}$, Jon Endri' ${ }^{2}$ Sarjana $^{3}$ \\ 123 Polsri, Telekomunikasi, Politeknik negeri sriwijaya, Palembang, Indonesia \\ 1irvanzar@gmail.com,2jonendri@polsri.ac.id,33anna.sarjana@gmail.com,
}

\begin{abstract}
The development of information technology in this modern era has progressed very rapidly, many ways have been developed to store large amounts of data, one of which is to use a server. A server is a computer system that serves and controls client access that is connected to it. All activities that we do on the internet always involve the server. Servers play a very important role because of their heavy duty to serve clients. Therefore, the server may not experience interference. One of the disturbances that cause a damaged server is the temperature that is too hot so that this tool is made in order to prevent these problems. This tool is made to regulate the temperature and humidity of the server room that exceeds reasonable limits. This tool is made using Arduino Uno as a microcontroller, DHT11 as a temperature and humidity sensor, Ethernet shield as a link to the internet. This tool also uses the Blynk application as monitoring, from the results of reading temperature and humidity sensors on this device can reduce the temperature by $6^{\circ} \mathrm{C}$ cooler when the temperature in the room is hot, in this case the tool functions as it should
\end{abstract}

Keywords: ArduinoUno, Ethernet Shield, Internet of Things, DHT11

\begin{abstract}
Abstrak
Perkembangan teknologi informasi di era modern ini mengalami kemajuan yang sangat pesat, banyak cara yang dikembangkan untuk menyimpan data dalam jumlah besar salah satunya adalah menggunakan server. Server adalah sistem komputer yang melayani dan mengontrol akses client yang terhubung dengannya. Semua kegiatan yang kita lakukan di internet selalu melibatkan server. Server berperan sangat penting karena tugasnya yang berat untuk melayani client. Oleh karena itu, server tidak boleh mengalami gangguan. Salah satu gangguan yang menyebabkan server rusak adalah suhu yang terlalu panas maka dari itu alat ini dibuat agar dapat mencegah permasalahan tersebut. Alat ini dibuat untuk mengatur suhu dan kelembaban ruang server yang melebihi batas wajar. Alat ini dibuat meggunakan arduino uno sebagai mikrokontroller, DHT11 sebagai sensor suhu dan kelembaban, Ethernet shield sebagai penghubung ke internet. Alat ini juga menggunakan aplikasi blynk sebagai monitoring, dari hasil pembacaan sensor suhu dan kelembaban pada alat ini dapat menurunkan suhu sebesar $6^{\circ} \mathrm{C}$ lebih dingin pada saat suhu dalam ruangan panas, dalam hal ini alat berfungsi sebagai mana mestinya.
\end{abstract}

Kata Kunci: ArduinoUno, Ethernet Shield, Internet of Things, DHT11

\section{PENDAHULUAN}

Perkembangan teknologi yang pesat dalam bidang transfer data dan informasi menyebabkan penggunaan gadget dan perangkat pengolah data seperti laptop sangat banyak digunakan. User yang semakin banyak akan menyebabkan kinerja dari server berat dan panas. Server adalah sistem computer yang melayani dan mengontrol akses client yang terhubung dengannya. Semua kegiatan yang kita lakukan di internet menggunakan perangkat pengolah data dan informasi seperti laptop dan smartphone selalu 
melibatkan server. Oleh karena itu, sebuah server tidak boleh mengalami gangguan. Maka dari itu alat ini dibuat untuk mengatasi permasalahan tersebut.

\section{METODE PENELITIAN}

\subsection{Metode Penelitian}

Metode-metode yang dipakai oleh penulis pada penelitian kali ini adalah sebagain berikut :

a. Studi pustaka

Dalam proses penelitian ini penulis menggnakan referensi-referensi dari berbagai sumber seperti buku, jurnal, ensiklopedia, internet dan lainnya untuk mendapatkan data yang relevan agar dapat menunjang proses penelitian.

b. Konsultasi dan diskusi

Untuk mendapatkan informasi, teori-teori sebagai pendukung penelitian terkadang mencari dan membaca karya ilmiah tidaklah cukup dikarenakan ada beberapa yang tidak dimengerti. Oleh karena itu, berkonsultasi kepada dosen diperlukan agar lebih memahami referensireferensi yang telah dibaca sebelumnya. Berdiskusi kepada teman juga penulis lakukan untuk memperoleh informasi dan pendapat yang dapat mendukung proses penelitian.

c. Rancang Bangun Alat

Setelah mengumpulkan referensi dan informasi yang cukup penulis mulai melakukan perancangan pada alat yang akan dibuat. Perancangan terbagi menjadi dua bagian, yaitu perancangan perangkat keras (hardware) dan perancangan perangkat lunak (software). Dalam proses perancangan diperlukan ketelitian dan kesesuai urutan agar tidak terjadi kesalahan saat dalam proses perancangan. Adapun untuk memahami prinsip kerja dari alat yang akan dibuat maka dibuatlah diagram rangkian seperti yang terlihat dibawah ini.

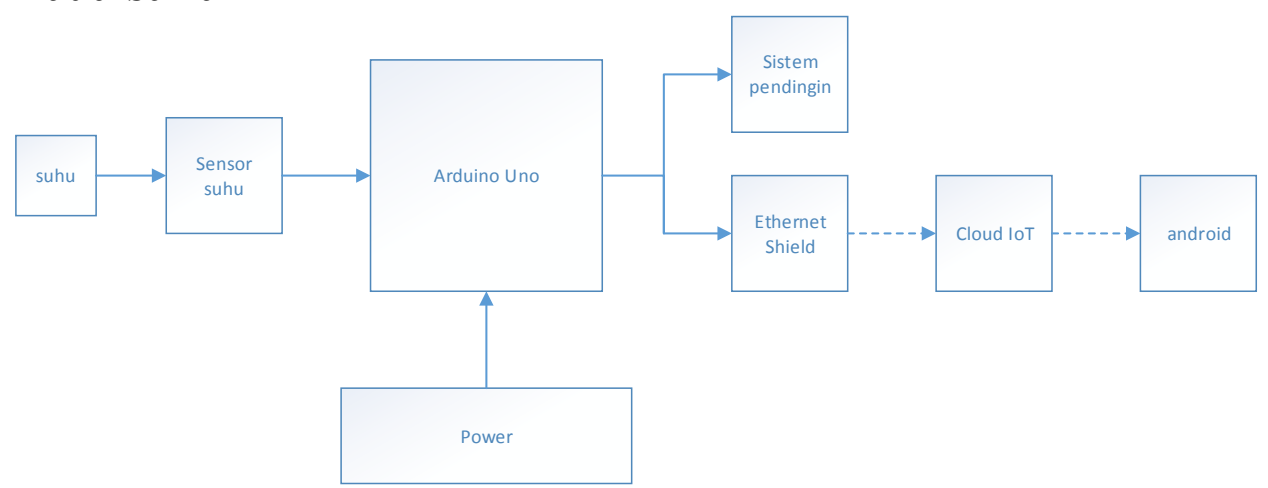

Gambar 1. Diagram Rangkain 


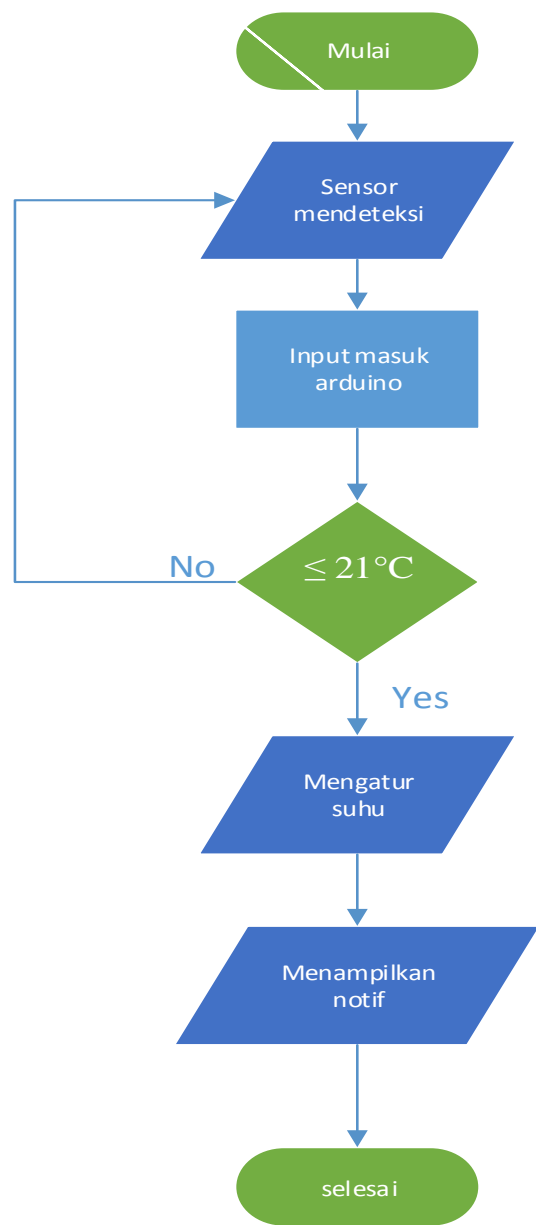

Gambar 2. Flowchart

d. Pengujian Alat

Setelah melalui proses pengumpulan data, perancangan alat, sampai pembuatan alat maka tibalah saatnya untuk menguji alat yang telah dibuat. Pengujian ini untuk mengetahui bahwa alat dapat bekerja. Pengujian memakai tiga kondisi yaitu yang pertama saat kondisi normal, kedua saat kondisi kotak simulasi ruangan panas, dan saat dinetralkan oleh pendingin

Tabel 1. Kondisi saat pengujian

\begin{tabular}{|l|c|c|l|}
\hline \multicolumn{1}{|c|}{ Kondisi } & Menit & $\begin{array}{c}\text { Suhu }{ }^{\circ} \mathrm{C} \text { dan } \\
\text { Kelembaban } \%\end{array}$ & \multicolumn{1}{c|}{ Ket } \\
\hline Suhu Normal & $1-5$ & 28,7 dan 87 & $\begin{array}{l}\text { Tanpa pendingin dan } \\
\text { pemanas }\end{array}$ \\
\hline Suhu Panas & $5-10$ & 33 dan 74 & Tanpa pendingin \\
\hline Suhu dinetralkan & $10-30$ & 27,4 dan 67 & Diberi pendingin \\
\hline
\end{tabular}




\section{HASIL DAN PEMBAHASAN}

\subsection{Pembahasan}

Pada saat pengujian data yang diambil memiliki 3 kondisi yang diantaranya :

a) Pada saat suhu normal dan didapatkan hasil baca dari sensor $28,7^{\circ} \mathrm{C}$ dan $87 \%$, pengujian dilakukan selama 5 menit tanpa diberi pemanas dan pendingin.

b) Pada saat Suhu panas dan didapatkan hasil baca dari sensor $33^{\circ} \mathrm{C}$ dan $74 \%$, pengujian dilakukan selama 5 menit diberi pemanas yang berasal dari air panas yang diletakkan dalam kotak, uap yang dihasilkan dari air panas menaikan suhu didalam kotak sekitar $5^{\circ} \mathrm{C}$ dan menurunkan kelembaban sekitar 14\%

c) Suhu saat dinetralkan mendapatkan pembacaan dari sensor $27,4^{\circ} \mathrm{C}$ dan $66 \%$, pengujian dilakukan selama 20 menit dan diberi pendingin untuk mendapatkan titik suhu terendah saat menetralkan kembali suhu.

d) Secara umum dari hasil pengujian alat ini berfungsi dengan baik karena terbukti mampu mendinginkan atau menurunkan suhu sekitar $6^{\circ} \mathrm{C}$. Panas yang dihasilkan dari pemanas $33^{\circ} \mathrm{C}$ dapat turun sampai $27,4^{\circ} \mathrm{C}$ dan kelembaban yang semula tinggi turun hingga $66 \%$.

\subsection{Hasil Perangkat}

Hasil yang didapatkan terhadap penelitian ini berupa alat pengatur suhu dan kelembaban ruangan. Alat ini bekerja pada suhu panas yang melewati batas yang telah ditentukan dan mengirimkan notif ke smartphone. Alat ini sangat berguna untuk operator dan maintenance ruang server.

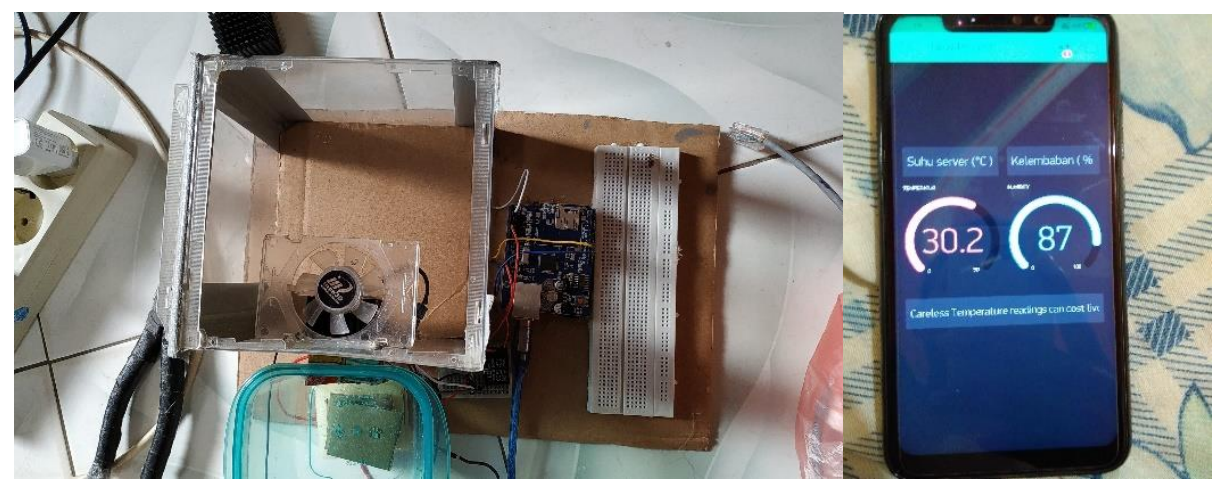

Gambar 3. Alat pengatur suhu dan kelembaban ruangan

\section{SIMPULAN}

Adapun simpulan dari penelitian yang dilakukan adalah:

a. Dari percobaan yang dilakukan sensor suhu bekerja dengan baik, pengukuran yang dilakukan dengan tiga kondisi yaitu kondisi normal saat tidak diberi pendingin atau pemanas, kondisi suhu panas saat diberi pemanas dan tidak di beri pendingin, kondisi netral yaitu saat 
Jurnal Sains Komputer \& Informatika (J-SAKTI)

Volume 3 Nomor 2 September 2019, pp. 178-182

ISSN:2548-9771/EISSN:2549-7200

http://tunasbangsa.ac.id/ejurnal/index.php/jsakti

diberi pendingin. Alat bekerja dengan baik karena sudah terbukti dapat mendinginkan dan tidak terjadi masalah yang berarti

b. Aplikasi di android juga tidak terdapat masalah saat dilakukan pengujian hanya saja jika sinyal pada operator buruk maka nilai yang dikirimkan dari sensor sedikit terlambat sampai.

c. Dari hasil pengujian, alat dapat bekerja dan menurunkan suhu panas didalam kotak sekitar $6^{\circ} \mathrm{C}$. Suhu panas yang semula $33^{\circ} \mathrm{C}$ dapat turun hingga $27,4^{\circ} \mathrm{C}$.

\section{DAFTAR PUSTAKA}

[1] P. Classification, “(12) Patent Application Publication ( 10 ) Pub . No .: US 2006 / 0287107 A1," vol. 1, no. 19, 2006.

[2] J. Eisenburg, "Zur Rehabilitationsbehandlung bei gastroenterologischen Erkrankungen.," Ther. Ggw., vol. 109, no. 12, p. 1739-1742 passim, 1970.

[3] Keputusan Menteri Kesehatan RI No. 1405/MENKES/SK/XI/2002 tentang Persyaratan Kesehatan Lingkungan Kerja Perkantoran dan Industri

[4] Kontributor Wikipedia. "Sensor suhu." Wikipedia, Ensiklopedia Bebas. Wikipedia, Ensiklopedia Bebas, 25 Okt. 2018. Web. 25 Okt. 2018.

[5] M. F. Awaj, A. F. Rochim, and E. D. Widianto, "Sistem Pengukur Suhu dan Kelembaban Ruang Server," J. Teknol. dan Sist. Komput., vol. 2, no. 1, p. 40, 2014. 